\title{
Peripheral Primitive Neuroectodermal Tumor of the Calcaneus: A case report
}

\author{
by Seyed Ali Hashemi, MD ${ }^{1 凶}$, Negar Azapria, MD ${ }^{2} \otimes$, Amir Reza Vosoughi, MD $^{3}{ }^{\square}$, \\ Masoome Pourmokhtari, MD ${ }^{4} \mathbb{a}$
}

The Foot and Ankle Online Journal 4 (6): 2

Ewing's sarcoma family of tumors is the second most common primary aggressive bone tumor especially in the late teenage years. We presented a 21 year-old man with swelling and pain of left heel. Imagings were in favor of osteomyelitis but no periosteal reaction was identified. Open biopsy revealed primitive neuroectodermal tumors. Finally, he underwent below knee amputation. Therefore, biopsy of lesions in calcaneus, especially without periosteal reaction, is strongly recommended.

Key words: Peripheral Primitive Neuroectodermal Tumor, Calcaneus, Ewing's Sarcoma.

Accepted: May, 2011

Published: June, 2011

This is an Open Access article distributed under the terms of the Creative Commons Attribution License. It permits unrestricted use, distribution, and reproduction in any medium, provided the original work is properly cited. @The Foot and Ankle Online Journal (www.faoj.org), 2011 All rights reserved.

$\mathrm{E}$ wing's sarcoma family of tumors (ESFT) is the second most common primary aggressive bone tumor in young patients. This entity consists of Ewing's sarcoma, Askin tumor, and peripheral primitive neuroectodermal tumors (PNET). ${ }^{1}$ They comprise the small, highly anaplastic, round, and blue cell tumors, cytogenetically confirmed by a $\mathrm{t}(11,22)$ or $\mathrm{t}(21,22)$. This genetic alteration can be detected with RT-PCR or FISH in fresh or paraffin-embedded material., ${ }^{2,3}$

Address correspondence to: Seyed Ali Hashemi, MD,

E-mail: sahashemi1411@gmail.com. Tel/ Fax: +98 7116234504.

Study was carried out in Research Center for Bone \& Joint Diseases, Chamran Hospital, Shiraz University of Medical Sciences, Shiraz, Iran.

\footnotetext{
${ }^{1}$ Assistant Professor of Orthopedic Surgery, Research Center for Bone \& Joint Diseases, Chamran Hospital, Shiraz University of Medical Sciences, Shiraz, Iran.

2 Assistant professor of pathology, Department of Pathology, Chamran Hospital, Shiraz University of Medical Sciences, Shiraz, Iran.

${ }_{3,4}$ Resident of Orthopedic Surgery, Research Center for Bone \& Joint Diseases, Chamran Hospital, Shiraz University of Medical Sciences, Shiraz, Iran.
}

They are seen more in males $(60 \%)$, especially in the late teenage years. ${ }^{4,5}$ The diaphysis of long bone, especially the femur, is the most common site. Foot involvement is rare and in this anatomical location, the calcaneus is the second most common site after the metatarsal bones. ${ }^{6}$

To our knowledge, there is no report of PNET of the calcaneus in the literature; although, we could find several cases of calcaneus Ewing's sarcoma. ${ }^{6-9}$ The important points in these reports were the same presentation and radiographs changes. Metastasis was the leading cause of death as described by Gupta, et al. A 19 year-old male died after 10 months due to pulmonary metastasis. Delay in diagnosis was because of treatment of the lesion as a tuberculosis infection instead of taking an open biopsy urgently. ${ }^{6}$ Metastasis to the tibia and fibula ${ }^{7}$ and meninges ${ }^{8}$ were also reported. 


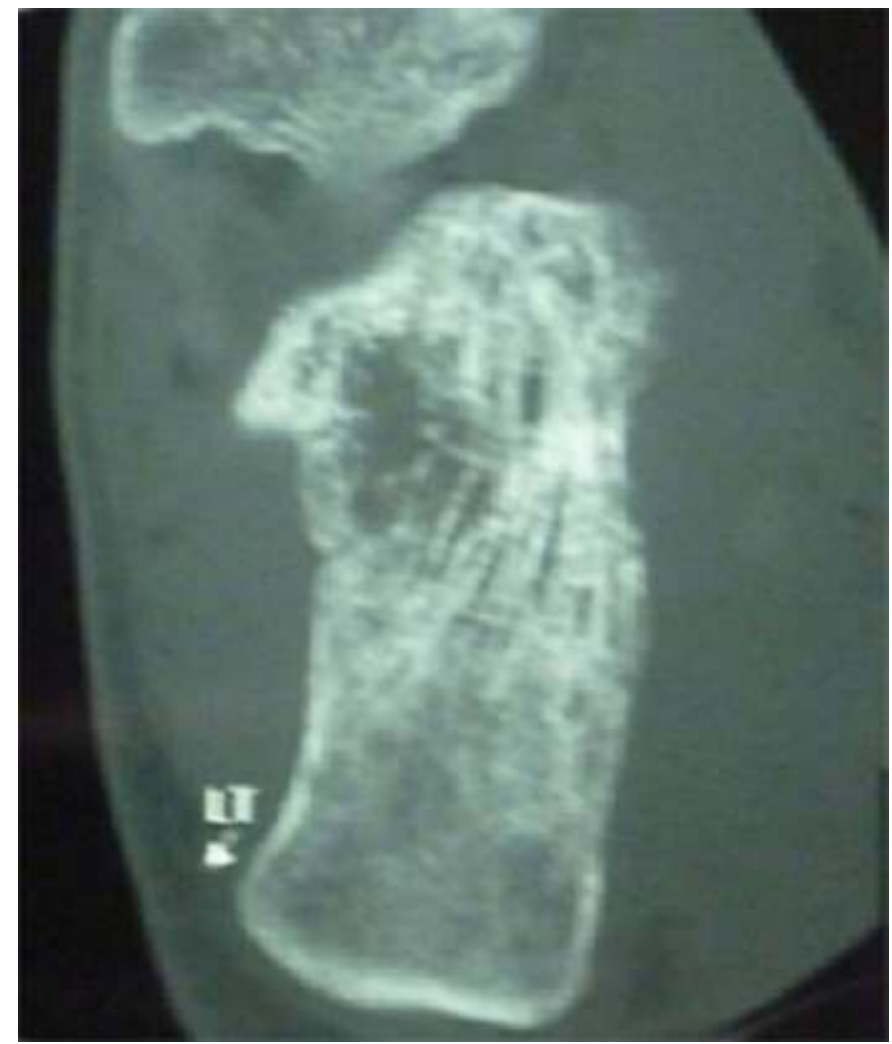

Figure 1 Axial computerized tomography scan revealed mixed osteolytic and osteoblastic changes without periosteal reaction.

\section{Case Report}

A 21 year-old man presented with swelling and pain of the left heel for seven months. The swelling had become increasingly severe since the time of admission. The patient had no history of trauma. His medical history was unremarkable. Physical examination revealed tenderness and swelling of the left heel with stretched overlying skin. There were no systemic symptoms. Laboratory tests were within normal limits.

Plain radiographs and computed tomogram (CT) showed osteolytic and osteosclerotic changes with cortical destruction in the left calcaneus without periosteal reaction. (Fig. 1) On magnetic resonance image, there was a $27 \mathrm{~mm}$ osteolytic lesion in the anterior aspect of the left calcaneus with cortical erosion and sclerotic change of other parts of the bone.

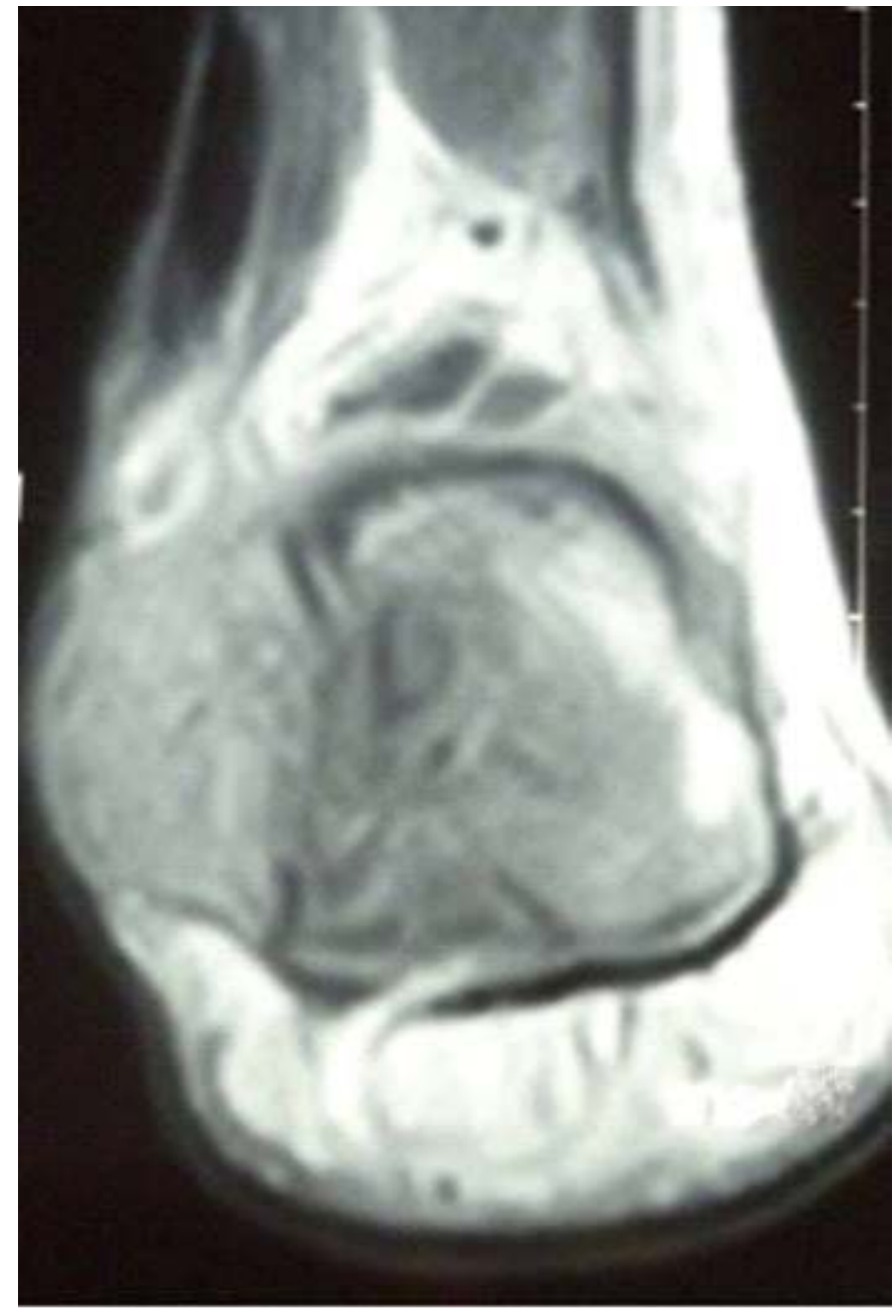

Figure 2 T2-weighted magnetic resonance image showed soft tissue mass with changes in bone.

It was hypointense on T1-weighted images and hyperintense in T2-weighted images. There was an obvious soft tissue mass on magnetic resonance imaging (MRI). (Fig. 2) The condition was thought to be chronic osteomyelitis versus tumor. Open biopsy was performed for final diagnosis.

On light microscopy, the tumor showed mainly a sheet of uniform small round cells with high nuclear/cytoplasmic ratios and finely dispersed chromatin infiltrated between muscle fibers. (Fig. 3) Some of the tumor cells arranged around the vessels were in a pseudorosette fashion. Areas of necrosis were also present. On immunohistochemical analysis, the cells had strong staining for CD99. (Fig. 4) 


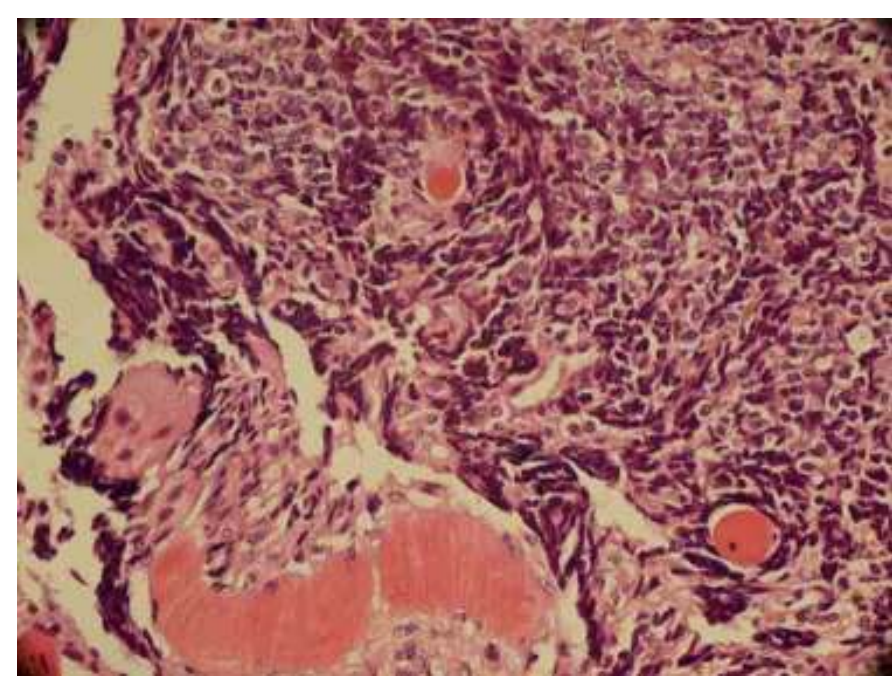

Figure 3 Infiltration of small malignant cells between muscle bundles $(H \& E \times 200)$.

Most cells stained positively for vimentin as well. Few clusters had some cells positive for synaptophysin and glial fibrillary acidic protein. Negative reactions with CD45, desmin and epithelial membrane antigen excluded other small round cell tumors such as lymphoma/leukemia and embryonal rhabdomyosarcoma. Overall, these findings were in favor of Peripheral Primitive Neuroectodermal Tumor. Computed tomogram study of the thorax and bone scan did not reveal any metastasis. He underwent a below knee amputation. After one year follow-up, the patient is alive with no evidence of recurrence or metastasis.

\section{Discussion}

ESFTs are malignant tumors with common histologic and molecular features but differing only in their extent of cellular differentiation. ${ }^{10}$ Its peak incidence is in patients ranging from 15 to 29 years old (2.9 per million per year). Fortunately, the incidence did not change in previous 20 years. Also, the fraction of patients with detectable metastases at diagnosis remained fairly stable at $20-25 \%{ }^{1,11}$

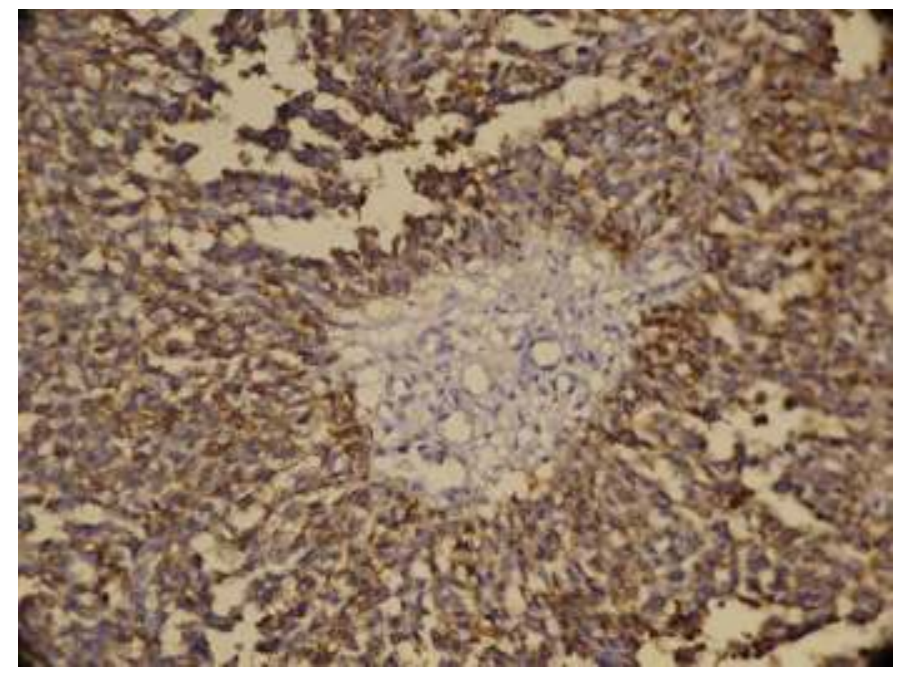

Figure 4 CD99 positive tumor cells in immunohistochemistry $($ IHC $\times 200)$.

There are some factors showing poor prognosis, such as: adult age, female gender, Hispanic race, metastases, large tumor $(>8 \mathrm{~cm})$, low socioeconomic status, pelvic primary tumor, high erythrocyte sedimentation rate, and high alkaline phosphatase. ${ }^{12,13}$

The most common presenting symptom is pain; although it is not a good indicator of malignancy. Swelling and palpable mass usually are seen. Most patients have normal laboratory studies but some may have elevated ones. ${ }^{2,14}$ Radiographs usually shows mixed radiolucent and radiodense lesions with permeative pattern and periosteal reaction in different forms (lamellated, parallel, speculated, perpendicular or mixed). Usually ESFTs of the foot make a diagnostic challenge for orthopedics surgeons. Because: 1) These tumors are rare in the foot and delay in diagnosis is a common problem. 2) Often radiographic appearances are similar to other parts involvement (cortical erosions, lytic lesions, and soft tissue mass), but lack of periosteal reaction and other features suggesting aggression sometimes may be seen. $^{15,16}$ 3) A great early misdiagnosis of these tumors especially in the foot is osteomyelitis due to the similarity in radiographic features. Mortality is more in patients with the initial diagnosis of osteomyelitis. ${ }^{17}$ Different parts of body may be involved by these tumors as metastases. ${ }^{7,8}$ 
Microscopically, monotonous population of uniform small round blue cell tumors, slightly larger than normal lymphocyte, with scant cytoplasm and round nuclei are seen in ESFTs. ${ }^{18}$ PNET is differentiated from other members by more neuronal differentiation. ${ }^{9}$

Membrane staining for CD 99, transmembrane protein encoded by the MIC 2 pseudogene located in the short arm of chromosome $\mathrm{X}$ and $\mathrm{Y}$, is seen in almost all cases of this tumor family. ${ }^{10,18}$ Lymphoblastic lymphoma/acute lymphoblastic leukemia, rhabdomyosarcoma, small cell osteosarcoma, and metastatic neuroblastoma should be considered in differential diagnosis. The most useful, though nonspecific, marker in the diagnosis of PNET is CD99, with a diffuse membranous staining pattern in these tumors. This protein is also highly expressed lymphoblastic lymphoma/acute lymphoblastic leukemia and rhabdomyosarcomas. The leukemic cells stain with terminal deoxytransferase (TdT) and clear cut matrix production by malignant cells is necessary for diagnosis of osteosarcoma. Myo D1 and desmin expression are in favor of rhabdomyosarcoma. The presence of neural markers such as such synaptophysin, S100, and chromogranin in an EFT indicates neuroectodermal differentiation (PNET). ${ }^{10}$

Although limb salvage procedures such as large frozen allogenic graft of femoral head and neck ${ }^{19}$ and distally pedicled osteomyocutaneous folded fibular flap ${ }^{20}$ were introduced in recent years, amputation is recommended in a patient with a high grade calcaneal sarcoma with a large soft tissue mass without metastases beside chemoradiotherapy. ${ }^{14}$

\section{References}

1. Balamuth NJ, Womer RB. Ewing's sarcoma. Lancet Oncol 2010 11(2): 184-92.

2. Heare T, Hensley MA, Dell'Orfano S. Bone tumors: osteosarcoma and Ewing's sarcoma. Curr Opin Pediatr 2009 21(3): 365-72.
3. Carvajal R, Meyers P. Ewing's sarcoma and primitive neuroectodermal family of tumors. Hematol Oncol Clin North Am 2005 3: 501-525.

4. Kilgore WB, Parrish WM. Calcaneal tumors and tumor-like conditions. Foot Ankle Clin 2005 10: 541-565.

5. Weber K, Damron TA, Frassica FJ, Sim FH. Malignant bone tumors. Instr Course Lect 2008 57: 673-88.

6. Gupta V, Mittal R, Rastogi S, Khurana J. Ewing's sarcoma of os calcis: case report with a review of literature. J Foot Ankle Surg 1999 38: 61-65.

7. Agarwal N, Sabir AB. Ewing's sarcoma of the calcaneus with metastases to the tibia and fibula. Acta Orthop Belg 2008 74(2): 270-272.

8. Bouchoucha S, Ben Hassine A, Douira W, Smida M, Nessib MN, Ammar C, Boussen H, Ben Ghachem M. Meningeal metastasis in Ewing's sarcoma of os calcis: case report. Tunis Med 2008 86: 509-510.

9. Choi JH, Yeo JH, Kim MJ, Shin DS, Cho KH. Ewing's sarcoma of the calcaneus: A case repot. Yeungnam Univ J Med 2004 21: 256-261.

10. Hameed M. Small round cell tumors of bone. Arch Pathol Lab Med 2007 Feb;131(2):192-204.

11. Eyre R, Feltbower RG, James PW, Blakey K, Mubwandarikwa E, Forman D, McKinney PA, Pearce MS, McNally RJ. The epidemiology of bone cancer in 0 - 39 year olds in northern England, 1981 - 2002. BMC Cancer 2010 10: 357.

12. Lee J, Hoang BH, Ziogas A, Zell JA. Analysis of prognostic factors in Ewing sarcoma using a population-based cancer registry. Cancer 2010 116(8): 1964-1973.

13. Casadei R, Magnani M, Biagini R, Mercuri M. Prognostic factors in Ewing's sarcoma of the foot. Clin Orthop Relat Res 2004 (420): 230-238.

14. Lietman SA, Joyce MJ. Bone sarcomas: Overview of management, with a focus on surgical treatment considerations. Cleve Clin J Med 201077 (Suppl 1): S8-12.

15. Reinus WR, Gilula LA, Shirley SK, Askin FB, Siegal GP. Radiographic appearance of Ewing sarcoma of the hands and feet: report from the Intergroup Ewing Sarcoma Study. AJR Am J Roentgenol 1985 144(2): 331-336.

16. Escobedo EM, Bjorkengren AG, Moore SG. Ewing's sarcoma of the hand. AJR Am J Roentgenol 1992 159(1): 101102.

17. Metcalfe JE, Grimer RJ. Ewing's sarcoma of the foot masquerading as osteomyelitis. Foot Ankle Surg 2004 10: 29-33.

18. Li S, Siegal GP. Small cell tumors of bone. Adv Anat Pathol 2010 17(1): 1-11.

19. Woźniak W, Raciborska A, Walenta T, Szafrański A, Szymborska A, Bajor M. New technique of surgical treatment of malignant calcaneal tumours. Preliminary report Ortop Traumatol Rehabil 2007 (3): 273-276.

20. Li J, Guo Z, Pei GX, Wang Z, Chen GJ, Wu ZG. Limb salvage surgery for calcaneal malignancy. J Surg Oncol 2010102 (1):48-53. 